\title{
Rituais políticos e representações do passado: sobre os funerais de "homens de letras" na passagem do império à república
}

\author{
Douglas Attila Marcelino[1]
}

\begin{abstract}
Resumo
Este artigo propõe uma análise dos funerais de "homens de letras" dentro do plano mais geral das transformações nos rituais políticos e nas formas de consagração cívica que caracterizaram o período final do império e início da república. Pretende-se indicar uma leitura ampliada desse tipo de eventos, que aponta suas vinculações com um regime de memória determinado e com transformações mais profundas em modos diversos de dar sentido ao passado. Alterações nas formas da escrita da história, das biografias e nas práticas de monumentalização adquirem particular relevância nesse tipo de reflexão, que não implica desconsiderar as especificidades dessas diferentes práticas letradas ou gêneros de discursos.
\end{abstract}

Palavras-chave: funerais cívicos; homens de letras; escrita da história.

Political rituals and representations of the past: about the funeral of "men of letters" in the transition from empire to republic

\begin{abstract}
This article proposes an analysis of the funerals of "men of letters" within the most general level of changes in political rituals and forms of public consecration that characterized the late period of the empire and early republic. It is intended to present a comprehensive reading of such events, showing its relation to a particular memory system and more profound transformations in different ways to make sense of the past. Changes in the forms of written history, biographies and practice of monumentalization take on particular importance in this way of thinking, which does not imply disregarding the specificity of these different literary practices or discourse genres. Keywords: civic funerals; men of letters; writing of history.
\end{abstract}

Rituels politiques et représentations du passé: à propos des funérailles des «hommes de lettres» dans la transition de l'empire à la république

\section{Résumé}

Cet article propose une analyse des funérailles des « hommes de lettres » au niveau plus général des transformations des rituels politiques et formes de la consécration publique que ont caractérisé la dernière partie de l'empire et au début de la république. L'intention est de présenter une lecture compréhensive de ce type dévénements qui montre ses liaisons avec un certain régime de mémoire et les transformations plus profondes des différentes façons de donner du sens aux passé. Des changements dans les formes de l'histoire écrite, les biographies et les pratiques de monumentalisation ont une importance particulière dans ce type de réflexion, et que n'implique pas négliger les spécificités de ces différentes pratiques lettrées ou genres de discours.

Mots-clés: funérailles civiques; hommes de lettres ; écriture de l'histoire.

Rituales políticos y representaciones del pasado: sobre el funeral de "hombres de letras" en la transición del imperio a la república

\section{Resumen}

Este artículo propone un análisis de los funerales de los "hombres de letras" en el nivel más general de las transformaciones en los rituales y formas de consagración cívica que caracterizaron el período final del imperio y el comienzo de la república. Se tiene la intención de presentar una lectura ampliada de este tipo de eventos que muestra su relación con un sistema de memoria particular y con transformaciones más profundas en diferentes maneras de dar sentido al pasado. Los cambios en las formas de la historia escrita, de las biografías y en las prácticas de monumentalización adquieren particular importancia en este tipo de reflexión, lo que no implica ignorar las especificidades de estas diferentes prácticas letradas o géneros de discursos.

Palabras clave: funerales cívicos; hombres de letras; escritura de la historia. 


\section{Introdução}

$\mathrm{C}$

onjunturas históricas de mudanças intensas são sempre acompanhadas da recomposição de expectativas, da conformação de novos valores e concepções de mundo, da produção de uma agenda simbólica e explicativa visando a dar coerência às experiências vividas. O século XVIII, marcado pela "filosofia das Luzes" e pela Revolução Francesa, é certamente um momento exemplar nesse sentido, que permitiu o estabelecimento de um ideário republicano com intenso potencial de repercussão em várias partes do mundo ocidental. Junto com os ideais da "Ilustração", uma nova "economia da glória", centrada na exaltação dos "grandes homens", tenderia a redefinir os velhos modelos de consagração heroica que ainda perduravam no Antigo Regime (Bonnet, 1997 e 1998). Crescentemente desprovido de um ideal de sacralidade ou de mecanismos que o distinguiam pelo nascimento e origem social, o grande homem das Luzes seria celebrado pelo mérito e pelas supostas virtudes cívicas, promovendo certo deslocamento em relação às representações que remetiam ao "herói guerreiro" ou às imagens clássicas do "varão ilustre plutarquiano" (Dosse, 2009).

Não obstante a glorificação dos "heróis" e "mártires" da causa revolucionária tenha, em fins do oitocentos, revalorizado elementos transcendentes diante de um discurso que sacralizava entidades próprias ao mundo político, a constituição de certo ideal de humanidade que acompanhava uma crescente secularização dos horizontes de expectativas tendia a fortalecer o teor meritocrático do discurso republicano em torno dos "grandes homens" (Ozouf, 1984 e 1976; Baczko, 1978). A institucionalização do elogio acadêmico desde meados daquele século indica como essa reconfiguração dos modelos de heroicidade atuava tanto no plano do imaginário quanto no das práticas letradas, sugerindo, inclusive, que ambos não deveriam ser tratados de forma separada (Bonnet, 1997; Roche, 1978 e 1988). As formas de glorificação recém-inauguradas seriam pródigas na exaltação desse novo tipo de personagem, cada vez mais aproximado do "homem comum", que, movido por ideais humanitários, não proviria apenas dos estreitos quadros do mundo nobiliárquico, figurando por suas próprias qualidades cívicas em uma verdadeira "república de talentos".

Tais mudanças, sem dúvida, são fundamentais para explicar a relevância que os funerais de Estado ganharam dentro da tradição republicana. Como nenhum outro, o regime republicano tornou aquele um importante ritual de exaltação dos "grandes homens" e suas virtudes cívicas, não obstante, é claro, a organização de grandiosos "funerais consagratórios" pelo Estado seja um fenômeno com raízes muito mais longínquas. Considerando apenas o caso francês, poderíamos dizer que os funerais reais de toda tradição litúrgica monárquica serviriam para exemplificá-lo. ${ }^{2}$ Segundo Avner Ben-Amos, por outro lado, na

${ }^{2}$ No caso dos funerais reais, foi no século IX que esse tipo de cerimonial ganhou importância, chegando a seu ápice nos séculos XV e XVI, com a introdução da efígie substituindo o corpo do monarca nas procissões realizadas pelas ruas parisienses (Ben-Amos, 2000; Giesey, 1960; Kantorowicz, 1998). Mudanças relevantes ocorreriam nos séculos XVII e XVIII, com a realização de rituais mais restritos à corte, em Versalhes, e toda 
história da monarquia francesa os funerais nunca rivalizaram em importância com outros tipos de cerimônias, como o ritual de coroação (Ben-Amos, 2000, p. 17-18). No regime republicano, os funerais de Estado teriam assumido um estatuto simbólico singular, transformando a Terceira República no primeiro regime a celebrar regularmente as exéquias de figuras não propriamente políticas, como cientistas e escritores de reconhecida notoriedade (Ben-Amos, 2000, p. 12).

Se essas alterações devem ser compreendidas dentro do quadro mais amplo de redefinições dos modelos de heroicidade e virtudes cívicas ensejados pela difusão das tradições republicanas, não se podem desconsiderar suas singularidades em diferentes países. Torna-se fundamental compreender as transformações que caracterizaram os rituais políticos no caso brasileiro dentro desse quadro mais amplo, inclusive considerando também suas peculiaridades em relação às práticas de culto cívico dos mortos da tradição portuguesa. Vários estudos têm tratado das especificidades do republicanismo em Portugal, alguns deles, inclusive, tecendo comparações com o caso brasileiro ou concentrando-se nos próprios ritos mortuários e práticas cemiteriais de consagração cívica. ${ }^{3}$ A comparação ganha especial relevância quando percebemos que, no caso brasileiro, muitos dos cerimoniais dispensados aos "grandes homens" parecem ter sido caracterizados por traços semelhantes àquilo que Fernando Catroga encontrou em sua análise das comemorações lusitanas, como certa meritocracia de teor mais aristocrático e uma maior ênfase não em acontecimentos, mas em personagens (Catroga, 2005, p. 126), o que parece sugerir uma cultura republicana caracterizada por traços de personalismo peculiares, discrepantes da tradição francesa.

Como se pretende indicar, essas e outras especificidades que caracterizaram as práticas cívicas de culto dos mortos podem ser compreendidas no quadro mais amplo de um regime de rituais determinado, tendo em vista, por exemplo, os limitados investimentos simbólicos que o regime monárquico-constitucional impunha à celebração dos mais "ilustres representantes da nacionalidade" no Brasil do oitocentos. Nessa perspectiva, certas peculiaridades assumidas pelas liturgias do poder da realeza são consideradas em relação às transformações em práticas como a escrita biográfica e a produção de monumentos, tal como ocorreria também com as formas de escrita da história e da produção de narrativas diversas que reconfiguravam o passado nacional, sobretudo se

a reconfiguração simbólica característica do imaginário do absolutismo, segundo a qual o corpo físico do rei passaria a absorver o corpo político do reino. Embora o caráter mais restrito dos novos cerimoniais já tenha sido relativizado, tendo em vista a presença de muitos visitantes em Versalhes e a difusão de imagens dos rituais por meio de toda uma ampla iconografia (Chartier, 2009, p. 188ss.), Avner Ben-Amos ressaltou ter havido, de fato, um investimento simbólico menos significativo nos funerais de Luís XIII, Luís XIV e Luís XV (Ben-Amos, 2000, p. 19).

${ }^{3}$ Fernando Catroga tem dedicado vários estudos ao republicanismo português e às comemorações cívicas de cultos dos mortos (conferir, especialmente, Catroga, 2010, 2005 e 1995). Sendo muitos os estudos sobre os republicanismos português e brasileiro, podem-se destacar aqui apenas algumas obras coletivas, sobretudo as de teor comparativo (Morais, Pires, Teixeira, Pereira, Rollo, Almeida e Castelo-Branco, 2014; Silva, Carneiro e Salmi, 2011; Homem, Silva e Isaía, 2007; Gomes e Mourão, 2011). 
considerarmos a crescente consolidação de um novo regime de práticas rituais mais adequado ao imaginário republicano em fins daquele século.

É claro que tais mudanças não ocorriam de forma determinista, tornando necessário considerar as diversas formas de dar sentido ao passado então existentes em suas devidas singularidades (as particularidades do gênero biográfico ou histórico, por exemplo). Ainda assim, uma análise das alterações nas formas de ritualização do poder a partir das mudanças nas modalidades de consagração cívica, como no caso dos funerais de escritores e outros personagens reconhecidos por suas atividades no campo letrado, tem implicações relevantes para pensarmos uma reconfiguração dos regimes de temporalidade adequados às novas formas de racionalidade e sensibilidade políticas. ${ }^{4}$ Trata-se de transformações que afetam os próprios modos de conferir sentido ao passado, uma vez que as fórmulas de estruturação narrativa que permitem figurar a experiência do tempo são, elas também, historicamente condicionadas.

\section{Torna-se fundamental compreender as transformações que caracterizariam os rituais políticos no caso brasileiro dentro desse quadro mais amplo}

O objetivo deste artigo é justamente sugerir que o estudo dos funerais de alguns "homens de letras" no período final do império e nos primeiros anos da república pode auxiliar na compreensão do modo como as transformações nas formas de consagração cívica então existentes se relacionavam com alterações em outras práticas memoriais e rituais de natureza política. Apesar dos limites, os casos analisados são significativos, inclusive quando consideramos os investimentos simbólicos do regime republicano nos funerais de Machado de Assis, tendo em vista que sua consagração cívica esteve ligada, sobretudo, à atividade literária. Os discursos que caracterizaram suas exéquias parecem sugestivos de certa valorização do intelectual pela especificidade de sua prática letrada, não obstante a representação do "homem de letras" como sujeito autônomo em relação às contingências do mundo político seja uma construção que remonta, pelo menos, a fins do século XVIII. ${ }^{5}$ Trata-se aqui, mais especificamente, da maior autonomia conferida à atividade literária e sua relação com o ideário republicano, que fortaleceria a identificação já existente da figura do escritor como um dos símbolos da nacionalidade. ${ }^{6}$

\footnotetext{
${ }^{4}$ Uma relação entre as formas públicas de luto e os "regimes de historicidade" foi indicada no relevante trabalho de Emmanuel Fureix, mas sem maiores aprofundamentos (Fureix, 2009, p. 15).

5 Segundo Roger Chartier, essa seria uma das representações do "homem de letras", mais tradicional, que discreparia de outra também presente desde os fins do século XVIII, na qual a atividade intelectual aparecia relacionada com a maior participação nos ciclos de sociabilidades do mundo letrado (Chartier, 1997).

${ }^{6}$ É claro que a identificação do escritor como símbolo da nacionalidade está também relacionada com o que se convencionou chamar de "romantismo" e ao "iluminismo", não se restringindo ao ideário republicano, mas enfatiza-se aqui, sobretudo, o investimento do Estado na consagração do escritor como símbolo da genialidade nacional.
} 
A escolha se torna relevante quando consideramos que os estudos existentes sobre funerais de personalidades públicas do início do regime republicano tratam, de modo geral, de figuras que foram valorizadas tanto por suas atividades letradas quanto pela atuação no campo político (como no caso emblemático de Rui Barbosa, por exemplo). ${ }^{7}$ A confrontação com outros funerais ocorridos ainda no império, ou no momento logo seguinte à morte de Machado de Assis, por outro lado, permitirá matizar algumas interpretações de eventos correlatos, como aquela que considera a figura de Euclides da Cunha como inauguradora do culto à figura do escritor como herói nacional. Analisaremos de forma mais detida os funerais desses dois escritores, destacando também alguns aspectos importantes das exéquias de Arthur Azevedo, tendo em vista que sua morte ocorreu em um pequeno espaço de meses entre os falecimentos de Machado e Euclides. Essas análises poderão, futuramente, ser expandidas para um estudo mais pormenorizado dos funerais cívicos de escritores do período republicano, o que se tornaria inviável pelos objetivos e limites deste artigo. De todo modo, os casos selecionados servirão também para matizar a comparação já estabelecida entre a consagração cívica de algumas figuras notáveis do início do período republicano e elementos da teoria dos dois corpos do rei, cujas origens remontam à teologia política medieval. É preciso considerar as diferenças entre uma forma de compreensão do poder mais fortemente permeada por fundamentos transcendentes daquela que caracterizaria uma crescente sacralização de entidades imanentes do mundo político, característica do discurso cívico que permeava o ideário republicano. ${ }^{8}$

\section{Rituais políticos, padrões biográficos e funerais cívicos nos anos finais do império}

No Brasil, o estabelecimento de uma economia da glória de moldes iluministas, centrada no enaltecimento dos grandes homens, permearia a produção histórica dos membros do Instituto Histórico e Geográfico Brasileiro (IHGB) no século XIX. Criada em 1838, a agremiação foi integrada por um conjunto de letrados empenhados em prover os meios para a construção da história e da geografia nacional. Sem retomar assunto já estudado em pormenores, ${ }^{9}$ cabe

\footnotetext{
${ }^{7}$ Não se pretende desconsiderar também a estreita relação entre atividade letrada e militância política no período indicado, conforme já identificado por vários analistas (por exemplo, Gomes, 2009; Dutra, 2005; Sevcenko, 2003), tratando-se aqui de enfatizar certa representação da atividade intelectual vinculada ao imaginário republicano. Retomaremos o assunto mais adiante.

8 É claro que se tornaria impossível produzir aqui uma discussão aprofundada sobre o problema complexo da secularização/laicização do mundo, e não se pretende defender uma discutível separação completa entre o político e o religioso a partir da modernidade, mas cabe considerar as transformações que permitiram o fortalecimento do imaginário republicano no exame efetivo dos discursos produzidos por ocasião dos funerais consagratórios. Apesar da imensa bibliografia, concepções divergentes e recentes sobre a relação entre o político e o religioso no debate francês podem ser verificadas nos textos de Regis Debray e Marcel Gauchet (Debray, 1981; Gauchet, 1985). Sobre o papel dos rituais políticos dentro das novas formas de experimentação do religioso, conferir também o estudo de Claude Rivière (1995).

${ }^{9}$ Além dos relevantes e conhecidos trabalhos de Manoel Salgado Guimarães (1988 e 2011) e Lúcia Maria Paschoal Guimarães (1995 e 2006), novos estudos têm sido produzidos sobre o tema (ver, por exemplo, Hruby, 2009; Sousa, 2008).
} 
destacar que o ideal iluminista dos grandes homens marcaria a própria revista da instituição, que, entre 1839 e 1888, manteve uma seção de notas biográficas dedicadas aos "Brasileiros ilustres pelas ciências, letras, armas e virtudes, etc... ${ }^{10} \mathrm{O}$ desejo de perpetuação da memória dos “varões ilustres", na verdade, já tinha sido indicado nos discursos de fundação da agremiação, nos quais a atividade ganhava nítida centralidade (Barbosa, 2010; Cézar, 2003), e se manifestaria também em muitos outros artigos biográficos e necrológios que não constavam na seção mencionada.

Fora da revista, outras publicações também revelariam a importância do gênero biográfico, muitas delas produzidas por membros do Instituto e seguindo o formato das "galerias" e dos catálogos de homens célebres, que esquadrinhavam suas supostas ações em favor da nacionalidade. Aqui, o paralelo com outros contextos nacionais já apontados demonstra sua relevância, tendo em vista que as relações entre os novos padrões de escrita biográfica e as formas de exaltação dos "grandes homens" foi também sugerida em estudos sobre os casos francês e português, por exemplo (Dosse, 2009; Catroga, 2004). O sentido fortemente pragmático que atravessou a produção histórica do oitocentos brasileiro provavelmente contribuiu para tal. $\mathrm{O}$ visível teor moralizante e de exemplaridade de muitas das publicações da época, por outro lado, não impediu que a escrita biográfica incorporasse critérios e exigências de verdade e justiça semelhantes aos que caracterizavam a escrita da história sobre o passado nacional (Oliveira, 2011).

Uma compreensão das peculiaridades assumidas pelas formas de consagração cívica dos grandes homens no Brasil do oitocentos não pode desconsiderar sua relação com as especificidades do regime monárquico, particularmente no que diz respeito à centralidade ocupada pela figura imperial dentro do conjunto de rituais e liturgias que conferem significado aos modos de aparição e representação do poder. De modo geral, os cerimoniais políticos, praticamente todos voltados para o monarca até as décadas finais do império, acabariam por obscurecer um maior investimento ritual na pedagogia dos grandes homens. Assim, até por volta de 1870 os "vultos nacionais" viveriam à sombra dos monarcas, recolhendo apenas "as migalhas do culto dinástico": "o pai, fundador do Império, é um herói; o filho, pacificador e amigo dos sábios, enverga, sobretudo depois de 1870, as vestes comuns do grande homem" (Enders, 2000, p. 59).

A partir dos momentos finais do império, quando d. Pedro II foi cada vez mais apresentado como uma espécie de "monarca cidadão" (Schwarcz, 1998b, p. 124ss.), perfazendo aparições menos pomposas e orquestradas, parecem ter surgido mudanças importantes nos cerimoniais públicos, as quais se acentuariam bastante nas primeiras décadas republicanas. A iconografia do período é extremamente rica na indicação das alterações sofridas pelas formas de representação do poder: várias imagens de d. Pedro II sugerem a crescente

$\overline{10}$ O título da seção, que desapareceu da revista entre 1852 e 1856, sofreu alterações ao longo do tempo, tendo em vista a dificuldade de definir a nacionalidade dos biografados (Enders, 2000; Oliveira, 2011). 
simplicidade de suas vestimentas e a perda de importância simbólica dos ícones e símbolos da liturgia imperial (Schwarcz, 1998a; Mauad, 1997). Além disso, toda uma "retratística" surgida com o uso da fotografia demonstra que o mecanismo simbólico de legitimação social, durante o Segundo Reinado, era ainda fortemente baseado em um critério nobiliárquico de distinção, advindo da proximidade com o imperador, haja vista a preocupação da elite da época de construir uma autorrepresentação semelhante àquela do monarca. ${ }^{11}$ No Primeiro Reinado, por outro lado, as liturgias do poder também remetiam quase exclusivamente à figura de d. Pedro I, que não apenas reforçou a relação de continuidade com as tradições monárquicas portuguesas como procurou se colocar como único fundador do império. ${ }^{12}$

Além da centralidade da figura imperial, as próprias especificidades do IHGB como instituição, permeada por práticas e formas de sociabilidades de teor aristocrático, também não favoreciam uma mais ampla difusão da pedagogia dos grandes homens. Os próprios padrões cerimoniais de exaltação biográfica do Instituto indicam o caráter restrito dos mecanismos de difusão de práticas memorialísticas que se fortaleceriam no ideário republicano, sugerindo, inclusive, as especificidades implicadas no uso da palavra nação como fundamento da glória dos personagens consagrados. Talvez por isso, em sua análise sobre a biografia histórica no oitocentos brasileiro, Temístocles Cézar não tenha encontrado uma distinção clara entre as expressões "homem ilustre" e "grande homem", tendo em vista a complexidade do assunto quando consideramos o caso nacional (Cézar, 2003, p. 90).

Com efeito, os momentos finais do império demarcam alterações importantes nas formas de ritualização do poder, tendo em vista não apenas o paulatino deslocamento da centralidade da figura monárquica, mas o estabelecimento de novas formas de afetividade e sensibilidade que fixavam o espaço da rua como lugar fundamental de consagração cívica (Mello, 2007). Tais mudanças simbolizavam também uma relativamente menor centralização na produção escrita como forma de monumentalização dos grandes homens, embora indicassem igualmente uma ressignificação de certas práticas letradas (seja pelo papel particular assumido pelos jornais, seja pela reconfiguração das formas de escrita sobre o passado nacional) (Gomes, 2009). Essas alterações, que remetem à conformação de um novo regime de memória e de práticas rituais, são fundamentais para a compreensão do significado particular que os funerais, como mecanismos de glorificação assentados em uma pedagogia dos grandes homens, assumiriam no regime republicano. Encenados para um público mais amplo e caracterizados por um ideal pedagógico e moralizante que se

\footnotetext{
" Segundo lara Lis Souza, é possível perceber a constituição de um padrão fotográfico, "um trânsito de imagens, de retratos dos homens de Estado, do estadista, sugerindo uma natureza comum entre eles, que os bem distinguia de todas as outras gentes da sociedade brasileira" (Souza, 2009, p. 34-35).

12 O calendário cívico, fixado por lei em 1826, "ordenava-se em torno da comemoração de eventos nos quais dom Pedro I aparece como o único ou pelo menos o principal personagem" (Enders, 2010, p. 62). Há uma extensa e importante bibliografia sobre as especificidades dos cerimoniais da monarquia brasileira, como no que diz respeito às formas assumidas pelos rituais de coroação e de sagração do primeiro imperador (ver, por exemplo, Oliveira, 2009; Souza, 1999; Cardoso, 2003).
} 
fortaleceu na conjuntura indicada, os cerimoniais fúnebres de escritores tidos como representativos da nacionalidade adquiriram contornos específicos, que devem ser compreendidos conjuntamente com a elaboração de outros mecanismos destinados à difusão dos valores cívicos e patrióticos que perpassaram a recomposição das formas de ritualização do poder aqui ressaltadas.

\section{Até por volta de 1870 os "vultos nacionais" viveriam à sombra dos monarcas, recolhendo apenas "as migalhas do culto dinástico"}

Em vários outros contextos nacionais, os cientistas e grandes escritores tiveram papel fundamental na pedagogia dos "grandes homens", que ganharia mais força nos regimes republicanos. Segundo Avner Ben-Amos, o "grande escritor", na França da Terceira República, chegou a ser tomado como uma espécie de profeta, que teria uma força moral excepcional e grande capacidade de previsão do futuro (Ben-Amos, 2000, p. 241). ${ }^{13}$ O período seguinte aos anos 1870 viu se fortalecer o ideal dos grandes escritores de fama internacional, representativos da genialidade nacional. Juntamente com o estudo da história e da geografia, por outro lado, o da literatura tornou-se parte importante da educação cívica nas escolas republicanas, fornecendo modelos de ação patriótica para imitação e ensinando sobre a diversidade regional e linguística da França (Ben-Amos, 2000 e 1984). A escrita da história e parte importante das produções literárias assumiam traços característicos comuns, o que também ocorreu no caso português, conforme se pode notar pelos vínculos estreitos entre as formas assumidas pela historiografia, pela literatura de divulgação do passado nacional de modo mais geral e pela produção de livros voltados para o ensino de história. Nesse caso, a "sacralização cívica da literatura" acompanhava não apenas essas mudanças em textos históricos de natureza diversa, mas também as alterações no regime de rituais e comemorações cívicas, conforme se poderia verificar pelo estudo do que já foi chamado de "ritualizações da história" (Torgal, Mendes e Catroga, 1996). ${ }^{14}$

Não foi por menos, no caso brasileiro, que os poetas, assim como os padres, tiveram lugar singular no "panteão de papel" estabelecido pela seção já mencionada da revista do IHGB, aparecendo já nas primeiras edições (Enders, 2000). O investimento nos funerais como forma de consagração cívica, entretanto, seguia o caráter incipiente das outras formas de ritualização do império, como no que diz respeito à construção de monumentos. O então diretor da Academia Imperial de Belas Artes, Manoel de Araújo Porto-Alegre, que teve papel fundamental no longo processo que permitiu a inauguração da estátua

${ }^{13}$ São conhecidas, por outro lado, as conferências do historiador inglês Thomas Carlyle sobre o homem de letras como herói nacional, proferidas em 1840 (Carlyle, 2002).

14 "Ritualizações da história" é o título da parte final do livro. 
equestre de d. Pedro I, em 1862, reclamava dessa ausência em artigo publicado na revista do IHGB poucos anos antes:

Quando os nossos legisladores decretarem um panteão, não digo um edifício suntuoso, mas um lugar sagrado e decente, onde se recolham os restos mortais dos nossos beneméritos, onde o paisano repouse a par do general, e que nesse lugar, em dia marcado, vá o imperador derramar flores sobre essas sepulturas singelas, o Brasileiro verá que o ouro não é a única recompensa da terra, e que acima dela está a pobreza de um José Bonifácio de Andrada, a de um visconde do Cairu, e de um São Leopoldo [...]. ${ }^{15}$

Apesar da fragilidade desses investimentos memorialísticos, a centralidade conferida à figura de $\mathrm{d}$. Pedro I contrastava com as práticas celebrativas de culto cívico dos mortos quando consideramos aqueles que poderiam ser identificados como os "grandes homens" da nação brasileira. Morto dois anos depois em um navio que partiu de Paris para a capital do império, Gonçalves Dias serviria de argumento para uma matéria do jornal O Paiz bastante sugestiva do modo como a pedagogia dos grandes homens ainda se chocava com a imortalização do "herói guerreiro", "conquistador" ou "navegador":

Erguem-se monumentos ao guerreiro ilustre, que soube sustentar os brios da pátria no campo da batalha.

Erguem-se ao conquistador, que nadando em sangue para lisonjear a louca vaidade da nação foi plantar os marcos do país algumas milhas mais distantes.

Erguem-se ao navegador famigerado, que devassando os mares levou a luz e a civilização aos povos mergulhados nas trevas da selvageria.

Erguem-se a todos que trabalharam em prol da humanidade, e cujos nomes cercam a veneração das gerações que se vão sucedendo. Porque [sic] há de o poeta ficar em esquecimento, o poeta que em cada coração tem um monumento ${ }^{16}$

Não era apenas o desejo de um monumento consagratório ou a ausência de um Panteão, como ressaltado por Porto-Alegre, que indicavam os limites dos mecanismos de eternização pela lembrança, uma vez que personalidades fundamentais da elite letrada não contariam nem mesmo com um lugar de simbolismo especial para seu velório: morto em 1863, o ator João Caetano, assim como outros homens de seu tempo, seria velado em sua própria residência em um modesto cerimonial que pareceu contar, sobretudo, com familiares, amigos e artistas admiradores. ${ }^{17}$ Algo semelhante aconteceria com José de Alencar, falecido em 1877, em funerais nos quais se viam, principalmente, importantes autoridades e membros da elite letrada, sem uma mais expressiva

\footnotetext{
15 Porto-Alegre (1856). O trecho foi também citado por Armelle Enders (2000).

${ }^{16}$ O Paiz, São Luís, fl. 1, 11 nov. 1864. Note-se que se trata do jornal O Paiz editado no Maranhão, e não o do Rio de Janeiro.

${ }^{17}$ Correio Mercantil, Rio de Janeiro, fl. 1, 26 ago. 1863.
} 
presença popular. ${ }^{18}$ Aliás, mesmo o "herói guerreiro" e condestável do império, o duque de Caxias, morto em 1880, parece não ter contado com exéquias suntuosas. ${ }^{19}$ Nada comparável, é claro, aos funerais de outro militar, o marechal Floriano Peixoto, primeira personalidade do regime republicano a ter suas exéquias completamente custeadas pelo Estado em 1895. ${ }^{20}$

Os funerais de Floriano contariam com toda a expressividade simbólica advinda dos excessos consagratórios visando a legitimar o novo regime. $\mathrm{O}$ marechal teve seu corpo embalsamado para ser velado por alguns dias na igreja Cruz dos Militares e foi enterrado no cemitério São João Batista. Assim o jornal $O$ Paiz se referia à ausência de um Panteão Nacional para a consagração do militar:

Os representantes da Nação reclamaram o seu corpo para o Panteão Nacional, que será elevado, onde ele será recebido, conjuntamente com outros beneméritos da Pátria, mas, enquanto esse monumento não for construído, os restos do consolidador da República vão dormir ao lado dos de Benjamin Constant, o seu fundador e apontado pelos representantes da Nação no Congresso Constituinte como exemplo aos que tiverem de dirigir os destinos da nossa pátria $\left[\ldots . . .^{21}\right.$

Os funerais de Floriano Peixoto parecem indicativos de como, no início do regime republicano, a discrepância entre os cerimoniais de consagração dos chefes de Estado e dos "grandes homens" (que, em planos diversos, como o das letras, teriam contribuído para a construção da nação) era ainda muito significativa. Isso sem desconsiderar, é claro, que a morte logo após deixar o governo da nação no comando da nação acentuaria toda a dramaticidade característica de certos discursos republicanos, como nas palavras de Azevedo Cruz durante as solenidades dos funerais:

De joelhos! Todos de joelhos! Pois então não se ajoelham, cheios de dor, diante da primeira coisa, diante do dever, do respeito e da veneração ao maior homem que tem existido nesta Pátria, ao maior coração que aqui tem pulsado? De joelhos todos! Para que a humanidade inteira saiba que neste fim de século houve num país longínquo da América do Sul a figura extraordinária de um homem que abriu, como se fosse um sol, aréola no espaço luminoso, e que ninguém mais quer outra além das que fulguram imperecíveis sobre a sua campa! Brasileiros, de joelhos! ${ }^{22}$

\footnotetext{
${ }^{18}$ Diário de Notícias, Rio de Janeiro, fl. 1, 13 dez. 1877.

19 Duque de Caxias foi velado em sua casa, na rua Conde de Bonfim, em um funeral que "dispensou todas as honras: nem sequer consentiu que a voz do canhão saudasse pela última vez o guerreiro que partia. Veio para a tumba, novo Saladino, cercado só das boas ações que praticou" (Gazeta de Notícias, Rio de Janeiro, fl. 1, 10 maio 1880). Importante estudo sobre a monumentalização de Caxias foi feito por Adriana Barreto de Souza (2008).

${ }^{20}$ Segundo o jornal o Paiz, Floriano teria tido a "glória de ser neste país o primeiro homem ao qual o Estado faz os funerais oficiais" (O Paiz, Rio de Janeiro, fl. 2, 2 jul. 1895).

${ }^{21}$ Ibidem.

22 Ibidem.
} 
Nada de comparável encontraríamos nos funerais de Machado de Assis e outros homens reconhecidos por sua atuação no campo literário, conforme analisaremos no próximo item. Mesmo se compararmos com o caso português, no qual o Panteão Nacional foi criado apenas em meados do século XX, algumas diferenças parecerão significativas, tendo em vista que as comemorações do tricentenário de Camões, em 1880, tinham sido marcadas não apenas pela presença de grandiosos cortejos cívicos e, portanto, relevante investimento memorialístico, mas também por praticamente iniciar um ciclo de comemorações com efetivo impacto na opinião pública (Catroga, 2005, p. 122). Por outro lado, o mosteiro dos Jerônimos já funcionava como panteão de consagração cívica, recebendo os restos mortais de homens notáveis (do próprio Camões, em 1880, mas também de outros, como Alexandre Herculano, João de Deus e Almeida Garret), seguindo os passos do modelo francês, que já havia "imortalizado" figuras como Mirabeau, Voltaire e Rousseau ainda em fins do século XVIII (Ozouf, 1984).

A falta de um Panteão Nacional, no caso brasileiro, entretanto, não impediria perceber semelhanças, que, inclusive, parecem mais significativas com o caso lusitano, como a tendência à maior personalização das evocações memorialísticas (Catroga, 2005, p. 126). Em Portugal, a celebração de "figuras notáveis", como Camões, infante d. Henrique e Vasco da Gama, por exemplo, discreparia da centralização em acontecimentos fundadores que caracterizou a Terceira República francesa, como aconteceu com o 14 de Julho, ou mesmo os centenários da Revolução (em 1898) e da República (1892). No Brasil, o regime republicano estabeleceria também os dias de festividade nacional, decretados feriados, mas sua capacidade de legitimação do novo regime parece ter enfrentado dificuldades mais significativas (Oliveira, 1989, p. 182ss.). Os funerais cívicos de determinados escritores podem servir também como indicativos dessas singularidades, tornando possível perguntar se, apesar de seu caráter amplo, algumas formulações de Sérgio Buarque de Holanda acerca de uma "cultura da personalidade" de matriz ibérica, configuradora de nossas "raízes", não ajudaria a explicá-las (Holanda, 1995, p. 32ss.). Tais particularidades, entretanto, são aqui apenas sugeridas por meio dos casos analisados em seguida, tendo em vista os limites deste artigo.

\section{8-1909: as mortes de Machado de Assis, Arthur Azevedo e Euclides da Cunha}

O primeiro escritor brasileiro a ter realmente funerais consagratórios, marcados por uma participação popular mais expressiva e por homenagens centradas puramente em sua atividade literária, foi Machado de Assis em 1908. O investimento oficial do regime republicano na panteonização de figuras célebres apenas pela produção artística, vale ressaltar, já podia ser visto por ocasião da morte de figuras como Carlos Gomes, em 1896, tido como o primeiro músico verdadeiramente representativo da nacionalidade. Importante jornal 
do período descreveria a trasladação de seus restos mortais ao cemitério da Soledade, em Belém, como "um suntuoso préstito, composto de coches alegóricos, além do em que ia o corpo do glorioso maestro e muitos carros com centenas de coroas", indicando como um músico poderia também figurar no rol dos grandes homens conforme o ideário republicano. ${ }^{23}$ Mesmo os já mencionados Gonçalves Dias e José de Alencar, falecidos ainda no império, foram saudados nos jornais como o "primeiro poeta brasileiro" e, "incontestavelmente, o primeiro literato brasileiro", respectivamente. ${ }^{24}$ Entretanto, seus funerais não contaram com um investimento e uma participação popular mais expressivos, nem foram acompanhados da formulação de discursos tão significativamente sugestivos do ideal meritocrático característico da pedagogia dos grandes homens reforçada pela república.

Se julgarmos pelas matérias de relevantes jornais do período, o enterro de Machado de Assis teria tido "a imponência de uma grandiosa consagração cívica", em que "figurava a nação inteira, desde os representantes dos mais altos poderes públicos até a grande massa anônima do povo". ${ }^{25}$ Referindo-se ao evento como um "extenso préstito triunfal", um jornal do período destacava o "silêncio respeitoso da multidão que, contrita e enorme, se estendia pelo caminho afora", fazendo sentir "a intensidade vibrante daquela importante manifestação glorificadora". ${ }^{26}$ Sem desconsiderar que a indicação de uma presença massiva de populares nas praças diante das manifestações oficiais constitui um topos retórico com longa permanência em materiais como os jornais (Cardoso, 2003), pode-se perceber que os funerais de Machado de Assis, além de contar com certa presença popular, se beneficiaram de investimentos do Estado republicano em favor de sua consagração cívica.

O discurso do ministro da Justiça, Lyra Tavares, já no cemitério São João Batista, serviria não apenas para indicar o papel do governo, mas também o sentido pedagógico conferido à celebração daquele "cuja maior ambição consistiu sempre em enriquecer e opulentar o inestimável patrimônio da nossa cultura moral e intelectual".27 Ainda segundo o ministro:

\footnotetext{
Mandando fazer seus funerais, o governo cumpriu seu dever. Resta, entretanto, a todos nós, que admiramos a sua obra fecunda, a todos nós que conhecemos a influência decisiva que exerceu e exercerá ainda por muito tempo nas letras pátrias, perpetuar em monumento duradouro sua inesquecível memória. Saibamos honrar essa memória. Para homens do valor de Machado de Assis, não bastam lágrimas de saudade, é preciso a glorificação, para exemplo e ensinamento das gerações por vir. ${ }^{28}$
}

\footnotetext{
${ }^{23}$ Gazeta de Notícias, Rio de Janeiro, 21 set. 1896. Além de mencionar que "enorme foi a massa de povo" presente no cortejo fúnebre, o jornal ressaltou as pompas do cerimonial, realizado ao som da ópera 0 Guarani, de autoria de Carlos Gomes.

${ }^{24}$ O Paiz, São Luís, fl. 1, 11 nov. 1864; O Globo, Rio de Janeiro, fl. 1, 15 dez. 1877.

25 O Paiz, fl. 2, 2 out. 1908.

${ }^{26} \mathrm{Ibidem}$

${ }^{27}$ Ibidem.

${ }^{28} \mathrm{Ibidem}$
} 
Dentro dos moldes característicos do teor meritocrático presente nos discursos e no ideário republicano, a obra de Machado de Assis era enaltecida nos jornais destacando-se a grandeza literária de um homem célebre apenas por seu talento e esforço pessoal: "Sem outra preocupação de ordem geral além da literatura, ele, por seu único esforço, elevou-se de um simples e obscuro tipógrafo até a maior culminância na literatura nacional", ressaltava o jornal O Paiz. ${ }^{29}$ Em uma "terra de precoces, de desalentados, de estéreis", destacava ainda a matéria do periódico, o escritor despontaria como aquele que ascendeu "somente pelo prestígio de sua arte", por "sua obra puramente literária", e não por uma ativa militância política:

Este humilde, este plebeu - que começa como tipógrafo, filho de pais obscuros, adquire uma cultura vasta e sólida, atinge a incontestada culminância na literatura de seu país, sente a prestigiosa veneração de todos os que aí leem e pensam - e, no entanto, não traduz na sua obra imensa vestígio algum da imoderada vaidade, da grosseira satisfação do arrivismo, da pretensiosa sabedoria, de intolerância ou de rancor; ao contrário, a sua qualidade mais sedutora é uma natural distinção, uma nobreza, que não consiste, aliás, em contar as aventuras galantes dos fidalgotes [...]. ${ }^{30}$

Um dos fundadores da Academia Brasileira de Letras (ABL), em 1897, e logo em seguida eleito seu primeiro presidente, Machado de Assis contaria não apenas com o Silogeu como lugar de forte simbolismo para o velório, mas com o discurso fúnebre do orador oficial designado para representar a instituição. Em geral, esse tipo de discurso se pautava por uma pedagogia cívica, em que se ressaltava de fato a suposta humanidade do morto célebre, enfatizando-se não apenas seu talento e intenso esforço de dedicação à pátria, mas seus nobres ideais e bons sentimentos. Um forte secularismo, que mesclava valores iluministas, românticos e republicanos, tendia a afastar a celebração do modelo hagiográfico e da ênfase no caráter sobre-humano do falecido, indicando a necessidade de usar com ponderação qualquer possível comparação com a teoria dos dois corpos do rei, analisada no importante estudo de Ernst Kantorowicz (1998). ${ }^{31}$ Tal como no discurso presente no jornal antes referido, era uma suposta autenticidade, certa generosidade de sentimentos, enfim, aspectos que conferiam humanidade a essa figura singular por sua "genialidade" que ganhavam relevo. Assim se expressava Rui Barbosa como representante da ABL:

\footnotetext{
${ }^{29}$ O Paiz, fl. 1, 1o out. 1908.

30 O Paiz, fl. 2,2 out. 1908

${ }^{31}$ Referindo-se ao enterro de Rui Barbosa, João Felipe Gonçalves indicaria semelhanças com a teoria dos dois corpos do rei. Segundo o autor, "o que se salientava [nesses rituais] não era a humanidade do morto, sua matéria-prima comum aos outros (que a morte biológica poderia pôr em evidência, poder-se-ia pensar), mas sua supra-humanidade, seu caráter excepcional. A retórica fúnebre os alçava a um nível superior ao resto da humanidade e afirmava como natural sua posição hierarquicamente superior, no fundo a posição de todo o setor social de que faziam parte os 'excelsos defuntos"' (Gonçalves, 2000, p. 154).
} 
Eu, de mim, porém, não quisera falar senão do seu coração e da sua alma. [...] Não é o clássico da língua; não é o mestre da frase; não é o árbitro das letras; não é o filósofo do romance; não é o mágico do conto; não é o joalheiro do verso, o exemplar, sem rival entre os contemporâneos, da elegância e da raça, do aticismio e da singeleza no conceber e no dizer; é o que soube viver intensamente da arte, sem deixar de ser bom. [...] Modelo foi de pureza, correção, temperança e doçura: na família, que a unidade e a devoção do seu amor converteram em santuário; na carreira pública, onde se extremou pela fidelidade e pela honra; no sentimento da língua pátria, em que prosava como Luiz de Souza e cantava como Luiz de Camões; na convivência dos seus próximos, dos seus colegas, dos seus amigos, em que nunca deslizou da modéstia, do recato, da tolerância, da gentileza. ${ }^{32}$

De fato, mesmo as referências ao plano divino, também presentes no discurso de Rui Barbosa, devem ser compreendidas a partir do sentido singular que adquiriam dentro do imaginário republicano, tendo em vista a tendência à sacralização de certas entidades, como a pátria, a nação, ou mesmo a república, que remetiam não a um plano transcendente, mas ao mundo político, ainda que em uma perspectiva teleológica e progressiva de temporalidade. ${ }^{33}$ Era mesmo a suposta humanidade de Machado de Assis que figurava como elemento central, não havendo, inclusive, contradição com a presença de referências à onipotência divina, conforme se pode notar pelos valores enaltecidos nesse tipo de discurso:

Ao chegar a nossa hora, em vindo a de te seguirmos um a um no caminho de todos, velando-te a segurança da justiça da posteridade, teremos o consolo de haver cultivado, nas verdadeiras belezas da tua obra, na obra dos teus livros e da tua vida, sua idealidade, sua sensibilidade, sua castidade, sua humanidade, um argumento mais da existência e da infinidade dessa origem de todas as graças à onipotência de quem devemos a criação do universo e a tua, companheiro e mestre, sobre cuja transfiguração na eternidade e na gloria, caíam as suas bênçãos, com as da pátria, que te reclina ao seu seio. ${ }^{34}$

Poucos meses depois, um novo cerimonial de consagração cívica seria encenado pela morte de Arthur Azevedo. Novamente era a humanização, a aproximação da sua figura daquela do homem do povo, para quem supostamente escreveria com simplicidade, que marcaria os discursos. Caracterizado como "o intelectual com quem o povo brasileiro mais palestrou e que mais deu ao

\footnotetext{
${ }^{32}$ O Paiz, Rio de Janeiro, fl. 2, 2 out. 1908.

${ }^{33}$ Conforme já indicado, um tratamento mais detido do problema envolveria toda a enorme discussão acerca da sacralização da política a partir da modernidade, tal como nos debates sobre as noções de secularização e laicização, que não se tornam passíveis de tratamento mais aprofundado neste artigo. Uma análise ampla do fenômeno da secularização foi feita por Jean-Claude Monod (2002). Tratamentos do tema que parecem particularmente sugestivos podem também ser encontrados nos textos de Claude Lefort (1991, especialmente p. 249-295, e 2011) e Fernando Catroga (2006).

${ }^{34}$ O Paiz, Rio de Janeiro, fl. 2, 2 out. 1908.
} 
público o convívio do seu espírito", Arthur Azevedo teria tido "a rara fortuna de saber falar-lhe claramente, na simplicidade puríssima de sua prosa e fluência cristalina do seu verso, a linguagem encantadora da verdade e do amor" ${ }^{35} \mathrm{De}$ "natureza simples", de "ideias e práticas democráticas", Azevedo "tanto cortejava a opulência como apertava ou estendia a mão à pobreza, envolvendo na mesma atmosfera de delicada afabilidade todos quantos se aproximavam dele". ${ }^{36}$ O discurso emocionado de Coelho Neto, designado como orador pela ABL, era também ressaltado nos jornais, juntamente com o número supostamente elevado de pessoas em seu enterro, contando não apenas com os "grandes vultos" da nação, mas com muitos "anônimos", "desconhecidos" que, "compungidos" ou "acabrunhados de tristeza", representavam a "grande dor, generalizada por todo o país". ${ }^{37}$ Eram os traços de personalidade que humanizavam o "grande homem", tornando-o próximo ao homem comum por ser dotado de sentimentos nobres e espontâneos, que, de fato, ganhavam relevo. Nessa leitura, "não era, porém, Arthur Azevedo um rebuscado, a pretexto de arte: a sua psicologia de homem de letras como de homem particular resumia-se nestas três únicas palavras: simplicidade, naturalidade, bondade [...]".38

\section{A falta de um Panteão Nacional, no caso brasileiro, entretanto, não impediria perceber semelhanças, que, inclusive, parecem mais significativas com o caso lusitano}

Igualmente Euclides da Cunha, morto no ano seguinte, figuraria não apenas como o grande escritor brasileiro, mas como um homem que se aproximou do povo por revelar o verdadeiro Brasil, aquele do interior, do homem sertanejo. No discurso de Coelho Neto, feito nos cerimoniais de enterramento, Os sertões apareceria como um "livro primoroso", que teria vindo "mostrar à nossa pátria que, lá dentro, nessas grandes terras, há uma raça forte: a dos trabalhadores, dos sofredores, dos que plantam e colhem [...] a raça do caboclo, que tem naquele livro seu grande poema de reivindicação de direitos" ${ }^{39}$ Mais do que apenas representante da genialidade nacional, Euclides seria, portanto, um homem que "amava as regiões do Norte porque era o poeta da simplicidade, da suavidade, da natureza e, principalmente, o poeta dos humildes". ${ }^{40}$ Em jornais do país, ganhavam novamente destaque sua personalidade, seus sentimentos, ou mesmo o grande coração que acompanhava sua singular inteligência: "muito não era preciso para a diagnose daquela personalidade. Foi uma bela

${ }^{35}$ O Paiz, fl. 2, 24 abr. 1908

${ }^{36}$ Ibidem.

${ }^{37} \mathrm{lbidem}$

${ }^{38}$ O Paiz, fl. 2, 25 abr. 1908

39 Gazeta de Notícias, Rio de Janeiro, fl. 2, 17 ago. 1909.

${ }^{40}$ Ibidem. 
inteligência, dotada de imensa força expansiva, e aliada a um coração capaz dos mais altivos cometimentos".11

Expressão do engajamento do homem de letras de seu tempo, Euclides, além do talento literário, era exaltado como cientista e por seu espírito republicano, revelador das agruras do povo brasileiro, que era redescoberto em sua verdadeira identidade, humilde e sertaneja. Trata-se de diferença importante em relação a Machado de Assis, consagrado de forma mais estrita por sua atividade literária, além dos traços já ressaltados, que aproximavam a imagem do grande homem daquela do homem comum, por sua personalidade, sentimentos e espontaneidade. Conforme já destacamos, por outro lado, os cientistas, juntamente com os escritores, ocupavam lugar central dentro do panteão de celebridades a serem consagradas pela república. Juntamente com a atividade política, que ainda aparecia como forma de distinção com relevo singular em relação às práticas do mundo letrado, as composições literárias e os investimentos científicos tornavam Euclides da Cunha uma figura enaltecida pela descoberta da brasilidade encarnada não apenas no sertanejo, mas nas particularidades naturais do país, estimulando homenagens que pareciam repercutir o motivo edênico que tantas raízes deitou no imaginário romântico, além, naturalmente, dos relatos de nossos primeiros cronistas: ${ }^{42}$

O Brasil é a nação sul-americana que pode se gabar de ter tido uma melhor dúzia de escritores que sentiram e deram a sensação emotiva da sua terra, do seu ambiente, do seu sol, das suas aves, das suas florestas, da sua vida característica. Porém, Euclides é, entre todos, o mais possante, pois que é o que vai ao fundo, até a alma recôndita da terra e da vida, científica e sensitivamente. Ele abriu uma estrada nova, larga e clara, não só para os escritores brasileiros, senão para todos os chamados a interpretar novas e enormes formas da natureza, novas e colossais formas de vida. A mocidade do Brasil deve tomar a seu cargo o cuidado de que nessa estrada não cresça a erva do esquecimento. Bastar-lhe-ia adotar, como Decálogo, aquele soberbo prólogo que Euclides fez para "O inferno verde", de Alberto Rangel. Ali estão fortemente traçadas as novas vias, sobre a terra amazônica, ainda emergente do caos, como as criações genésicas da Bíblia - e é por ali que os fortes do novo tempo devem tratar de ir adiante. ${ }^{43}$

Após sua morte, a memória de Euclides da Cunha seria objeto de investimentos significativos no plano simbólico, o mesmo ocorrendo com Machado de Assis, talvez em uma escala diferenciada (Abreu, 1998 e 1994; Werneck, 2008). A comparação entre os dois casos deixa dúvidas sobre a afirmativa de que Euclides da Cunha teria sido o grande inaugurador do "culto ao escritor

41 O Paiz, fl. 1, 18 ago. 1909.

${ }^{42} \mathrm{O}$ tema foi tratado já por inúmeros autores. Particularmente interessantes na forma de abordagem, apesar da natureza distinta de suas elaborações, são o livro clássico de Sérgio Buarque de Holanda (1998) e o artigo de José Murilo de Carvalho (1998).

${ }^{43}$ O Paiz, fl. 1, 19 ago. 1909. 
como mártir nacional", 44 tendo em vista a importância conferida pelo governo republicano aos funerais de Machado de Assis. As exéquias deste, além disso, aparecem nos jornais do período caracterizadas por todos os elementos que conferem singularidades àquele tipo de evento dentro do novo ideário cívico republicano (desde uma supostamente expressiva participação popular até a realização de discursos pomposos e eloquentes por membros da elite política e letrada da época, inclusive em momentos-chave, como os do velório e do sepultamento).

Na verdade, os funerais de Machado de Assis parecem os mais indicativos do modo como personagens reconhecidos por atividades não diretamente identificadas com a política podiam, já naquela conjuntura, tornar-se sujeitos principais de rituais consagratórios com significativo investimento simbólico. É importante enfatizar que não se está sugerindo o início da identificação do escritor como representante da nacionalidade, uma vez que esse tipo de representação do homem letrado estava disponível anteriormente, mas que, naquele momento de alterações relevantes no regime de memória e de rituais políticos, tornava-se possível o investimento do Estado na consagração cívica de uma figura reconhecida apenas por sua atividade literária. É isso, portanto, que torna particularmente significativo o estudo de suas exéquias, sobretudo quando analisadas em relação aos funerais de outros "homens de letras" do período final do império e do início da república, conforme vimos fazendo. Até o momento da morte de Machado de Assis, quando já havia uma reconfiguração simbólica que tornava mais estabelecido o ideário republicano, não encontraríamos um uso tão significativo desses tipos de ritos e mecanismos de distinção social para conferir um lugar específico na história nacional a uma figura que não fosse também reconhecida por uma atuação mais evidente na esfera política.

\section{Sobre funerais cívicos e regimes de rituais políticos: sugestões de aprofundamento}

Ocorridos em apenas dois anos, os funerais desses três personagens permitem refletir sobre as formas assumidas por esse tipo de ritual com a crescente consolidação dos valores republicanos. É relevante notar que, no caso brasileiro, os eventos similares analisados por outros analistas estão praticamente todos referidos a figuras que tiveram atuação expressiva no campo político, não obstante muitos daqueles personagens terem também sido celebrados por suas práticas letradas (é o caso, particularmente, de figuras como Joaquim Nabuco e Rui Barbosa, mas também da própria representação de d. Pedro II como o "rei

\footnotetext{
${ }^{44}$ A expressão é de Regina Abreu, para quem "é com Euclides da Cunha que tem início o culto do escritor como mártir nacional, um culto organizado e de longa duração. Se os funerais de Victor Hugo, em 1885, assinalaram na França a entronização dos escritores no panteão dos grandes homens da nação, no Brasil, foram os funerais de Euclides da Cunha que marcaram o culto não apenas como grande homem, mas como herói nacional [...]" (Abreu, 1998, p. 281).
} 
filósofo"). ${ }^{45}$ Isso não quer dizer, é claro, que as atividades letradas não envolviam a política (a própria atuação de Machado de Assis à frente da ABL serviria de contraponto a essa pressuposição), inclusive quando consideramos a específica imbricação entre a militância política e a atuação no campo literário e científico no período. Trata-se aqui, de fato, daquilo que se convencionou identificar como a política, ou seja, uma participação nos eventos relativos à esfera pública e às dinâmicas da vida governamental. ${ }^{46}$

\section{Um forte secularismo, que mesclava valores iluministas, românticos e republicanos, tendia a afastar a celebração do modelo hagiográfico e da ênfase no caráter sobre- humano do falecido}

Para além dessas e outras especificidades antes indicadas, este artigo pretendeu sugerir que os funerais antes analisados podem ser compreendidos dentro do quadro mais amplo de mudanças nas formas de ritualização e consagração cívica que permearam a passagem do império ao período republicano, o que pressupõe um entendimento específico da relação complexa entre diversos modos de construção de sentido para o passado dentro de um regime memorial determinado. A recomposição das formas de consagração cívica, que permite visualizar modos diferenciados de celebração dos grandes homens, parece indicativa de alterações mais profundas não apenas nos mecanismos de ritualização do poder, mas nas formas de lidar com a temporalidade dentro de um regime ritual perpassado por uma mescla peculiar de valores diversos, sejam iluministas, românticos ou republicanos. Partir dessa leitura ampliada do estudo dos rituais permite pensar a relação entre os valores que atravessavam os funerais de grandes homens e as expectativas de futuro que configuravam formas determinadas de experimentação do tempo dentro do imaginário republicano, tendo em vista a vinculação específica que se estabeleceu, por exemplo, com a busca historicista das individualidades que singularizariam as nações, como ocorreu com certos escritores e determinadas personalidades supostamente representativas da genialidade do povo brasileiro.

O período de passagem do império para a república se caracterizou por alterações relevantes nas formas de escrita sobre o passado nacional, que acompanhavam as reformulações do regime ritual de consagração de personagens

${ }^{45}$ Conferir, por exemplo, os estudos sobre Floriano Peixoto (Simas, 1994), d. Pedro II (Guimarães, 2009; Fagundes, 2012), Joaquim Nabuco (Bonafé, 2008) e Rui Barbosa (Gonçalves, 2000). Sobre Joaquim Nabuco, conferir também o estudo de Giselle Venâncio acerca dos discursos que proferiu por ocasião das comemorações camonianas no Rio de Janeiro, em junho de 1880 (Venâncio, 2013). Rebeca Gontijo também apontaria elementos importantes sobre os funerais de Capistrano de Abreu ao analisar a construção de sua memória (Gontijo, 2013).

${ }^{46}$ Utilizando uma analogia com concepções caras à escola francesa de estudos do político, poderíamos falar aqui da política, e não do político, como fundamento constitutivo da vida humana (conferir, entre outros, Lefort, 1991, e Rosanvallon, 2010). 
e de eventos da história brasileira expressas em formas diversas de comemoração cívica. A própria conformação de uma nova geração de intelectuais a partir de 1870, já estudada por outros analistas, ${ }^{47}$ foi marcada por uma maior preocupação com a ampliação da circulação da produção letrada, aspecto constante dos anseios de reformas sociais que, na ótica da época, proviriam especialmente da ação pedagógica em favor da educação do "povo brasileiro". Alçado a elemento fundamental da elaboração letrada, por outro lado, o "povo brasileiro" devia não apenas ser "formado" para a participação no novo regime político, mas acabou também figurando, em obras como as de Euclides da Cunha e Capistrano de Abreu, por exemplo, como ícone-fundador da identidade nacional (nas figuras do homem do interior, o sertanejo, e do mestiço) (conferir, por exemplo, Oliveira, 2002, e Reis, 1998). ${ }^{48} \mathrm{O}$ aumento da preocupação com a circulação da produção histórica sobre o passado nacional, expresso também por meio de uma farta literatura cívico-pedagógica, pode também ser compreendido em suas vinculações com as mudanças no regime de memória e de práticas rituais aqui apontadas. ${ }^{49}$ As atividades relativas à educação formal, nesse caso, não estavam desvinculadas de transformações nas práticas comemorativas e cerimoniais que deveriam atuar nos planos das afetividades e sensibilidades, com relevantes objetivos de formação patriótica a partir de certo ideário republicano.

Essas e outras preocupações da elite letrada do período, assim como um conjunto diverso de práticas que configuravam as especificidades da atividade intelectual da época, têm relações estreitas com as singularidades assumidas pelo ensino de história e pela própria historiografia, não obstante seja relevante considerar as características peculiares desta última como forma de escrita (ou seja, como uma prática de natureza determinada, que envolve operações e procedimentos que não se confundem com outras atividades igualmente vinculadas a um regime particular de memória e de práticas rituais). Sugere-se aqui, portanto, que os rituais antes analisados podem ser compreendidos dentro desse plano mais geral de transformações nas formas de dar sentido ao passado nacional, assim como suas relações com as especificidades

\footnotetext{
${ }^{47}$ São muitas as obras sobre a chamada "geração de 1870", tornando inviável tentar citar todos os trabalhos importantes. Duas referências relevantes, com abordagens bastante distintas, são as obras de Roberto Ventura (1991) e Angela Alonso (2002).

48 O tema da formação do povo brasileiro, é claro, apareceria em uma extensa literatura do período, ampliando-se ainda mais na conjuntura posterior e caracterizando um conjunto significativo de obras que ultrapassam enormemente o caso dos dois autores mencionados apenas como exemplo.

${ }^{49}$ São muitas as obras representativas do ideal cívico-pedagógico que acompanhava as transformações sociais do início da república, ensejando uma maior preocupação com a instrução popular (para citar apenas alguns exemplos, consultar Bomfim e Bilac, 1923, Bilac e Coelho Neto, 1946; Romero, 1890 - as primeiras edições dos livros foram publicadas, respectivamente, em 1910, 1894 e 1890). Levantamentos importantes desse tipo de publicação foram feitos por André Botelho (2002) e Patrícia Hansen (2007). O livro A educação nacional (1890), de José Verissimo, é um bom exemplo de preocupações no sentido aqui apontado, contendo um diagnóstico sobre a educação pela história no Brasil que ressaltava a (suposta) existência de praticamente um único grande livro (História geral do Brasil, de Varnhagen), a circulação restrita da revista produzida pelo IHGB, a falta de uma maior preocupação com um ensino não limitado à enfadonha lista de grandes feitos e personagens, a existência de poucos monumentos, galerias de pinturas, coleções históricas e, particularmente, comemorações, festas nacionais com cantos patrióticos e músicas que permitissem formar um novo padrão cívico de participação na república (Gomes, 2009, p. 102-103; Verissimo, 1985).
} 
assumidas pela própria cultura política republicana, tendo em vista as contínuas reinvenções dessa tradição em momentos relevantes da história política brasileira. As relações entre essas formas diversas de ritualização do poder e do tempo, portanto, podem configurar objeto importante de análise, tendo em vista que as cerimônias funerárias não deixavam de manifestar uma estrutura narrativa que celebrava uma figura determinada por sua relação mais ampla com o passado nacional (e que, inclusive, pode ser compreendida por relação a determinada "cultura política" ou "cultura histórica"). ${ }^{50}$

Pesquisa realizada com financiamento do Conselho Nacional de Desenvolvimento Científico e Tecnológico (CNPq).

\section{Referências bibliográficas}

ABREU, Marcelo. Luto e culto cívico dos mortos: as tensões da memória pública da Revolução Constitucionalista de 1932 (São Paulo, 1932-1937). Revista Brasileira de História, v. 31, p. 105123, 2011.

ABREU, Regina de. Emblemas da nacionalidade: o culto a Euclides da Cunha. Revista Brasileira de Ciências Sociais, São Paulo: Anpocs, v. 24, n. 9, 1994.

. O enigma de Os sertões. Rio de Janeiro: Funarte/Rocco, 1998.

AGULHON, Maurice. Marianne au combat: l'imagerie et la symbolique républicaines de 1789 à 1880. Paris: Flammarion, 1979.

ALONSO, Angela. Ideias em movimento: a geração 1870 na crise do Brasil império. São Paulo: Paz e Terra, 2002.

BACZKO, Bronislaw. Les utopies et les fêtes. In:___ _. Lumières de l'utopie. Paris: Payot, 1978. p. 233-282.

BARBOSA, Januário da Cunha. Discurso no ato de estatuir-se o Instituto Histórico e Geográfico Brasileiro. In: GUIMARÃES, Manoel Salgado (Org.). Livro de fontes de historiografia brasileira. Rio de Janeiro: Eduerj, 2010.

BEN-AMOS, Avner. Funerals, politics, and memory in modern France, 1789-1996. Oxford/Nova York: Oxford University Press, 2000.

Les funérailles de Victor Hugo: apothéose de l'événement spectacle. In: NORA, Pierre (Ed.). Les lieux de mémoire: la république. Paris: Gallimard, 1984. p. 473-522.

BILAC, Olavo; BOMFIM, Manoel. Através do Brasil. Rio de Janeiro: Francisco Alves, 1923.

; COELHO NETO, Henrique Maximiano. Contos pátrios. Rio de Janeiro: Francisco Alves, 1946. BONAFÉ, Luigi. Como se faz um herói republicano: Joaquim Nabuco e a república. Tese (Doutorado em História), Universidade Federal Fluminense, Niterói, 2008.

\footnotetext{
${ }^{50}$ As noções de "cultura política" e "cultura histórica" foram tratadas por uma ampla bibliografia, impossível de ser analisada de forma sistemática neste artigo. Um importante levantamento foi feito por Daniel Cefaï (2001; conferir também leitura crítica em Dutra, 2002), e uma tentativa de diferenciação de ambas as noções foi formulada por Angela de Castro Gomes (2013). O importante livro de Luís Torgal, José Mendes e Fernando Catroga, já citado anteriormente, demonstra de forma interessante a relação entre essas diversas formas de conferir sentido ao passado nacional, englobando uma análise da historiografia, da literatura mais geral sobre o passado português, dos livros relativos ao ensino de história e das práticas comemorativas (Torgal, Mendes e Catroga, 1996). O próprio Fernando Catroga, por outro lado, denominaria comemorações como as aqui ressaltadas "liturgias cívicas", ou ainda "ritos móveis de história", enfatizando a estrutura narrativa que as caracterizaria (Catroga, 1998, p. 221, e 2003, p. 128). Para uma ênfase na estrutura narrativa das práticas rituais, que buscaria elementos para a compreensão de toda a retórica que caracterizaria as cerimônias cívicas, conferir o estudo de Paul Connerton (1999).
} 
BONNET, Jean-Claude. Les morts illustres. In: NORA, Pierre (Org.). Les lieux de mémoire: la nation. Paris: Gallimard, 1997. p. 1831-1854.

. Naissance du Panthéon: essai sur le culte des grands hommes. Paris: Fayard, 1998.

BOTELHO, André. Aprendizado do Brasil: a nação em busca de seus portadores sociais. Campinas: Unicamp, 2002.

CARDOSO, Ângela Miranda. Ritual: princípio, meio e fim. Do sentido do estudo das cerimônias de entronização brasileiras. In: JANCSÓ, István. Brasil: formação do Estado e da nação. São Paulo: Hucitec, 2003. p. 549-602.

CARLYLE, Thomas. Os heróis de Thomas Carlyle. Lisboa: Guimarães Editores, 2002.

CARVALHO, José Murilo de. A formação das almas: o imaginário da república no Brasil. São Paulo: Companhia das Letras, 1990.

. O motivo edênico no imaginário social brasileiro. Revista Brasileira de Ciências Sociais, São

Paulo, v. 13, n. 38, out. 1998. Disponível em: <www.scielo.br/pdf/rbcsoc/v13n38/38murilo.pdf>. . Os bestializados: o Rio de Janeiro e a república que não foi. São Paulo: Companhia das

Letras, 2005.

CATROGA, Fernando. A militância laica e a descristianização da morte em Portugal. Edição de João Luís Oliva. Viseu, 1995.

. Entre deuses e césares: secularização, laicidade e religião civil. Uma perspectiva histó-

rica. Coimbra: Almedina, 2006.

. Nação, mito e rito: religião civil e comemoracionismo. Fortaleza: Museu do Ceará, 2005. . O céu da memória: cemitério romântico e culto cívico dos mortos em Portugal (1756-

1911). Coimbra: Minerva, 1999.

. O magistério da história e a exemplaridade do "grande homem": a biografia em Oliveira

Martins. In: JIMÉNEZ, Aurélio P.; FERREIRA, José R.; FIALHO, Maria do C. (Org.). O retrato lite-

rário e a biografia como estratégia de teorização política. Coimbra: Imprensa da Universidade de Coimbra/Universidad de Málaga, 2004. p. 243-288.

Letras, 2010.

O republicanismo em Portugal: da formação ao 5 de outubro de 1910. Lisboa: Casa das

CEFAÏ, Daniel. Expérience, culture et politique. In:

(Org.). Cultures politiques. Paris: PUF, 2001. p. 93-116.

CÉZAR, Temístocles. Livros de Plutarco: biografia e escrita da história no Brasil do século XIX. Métis, Caxias do Sul: UCS, v. 2, n. 3, p. 73-94, 2003.

CHARTIER, Roger. O homem de letras. In: VOVELLE, Michel. O homem do Iluminismo. Lisboa: Presença, 1997. p. 117-153.

. Origens culturais da Revolução Francesa. São Paulo: Unesp, 2009.

CONNERTON, Paul. Como as sociedades recordam. Lisboa: Celta, 1999.

DEBRAY, Régis. Critique de la raison politique. Paris: Gallimard, 1981.

DOSSE, François. O desafio biográfico: escrever uma vida. São Paulo: Edusp, 2009.

DUTRA, Eliana Freitas. História e culturas políticas: definições, usos, genealogias. Varia Historia, Programa de Pós-graduação em História da UFMG, n. 29, p. 13-28, 2002.

. Rebeldes literários da república: história e identidade nacional no Almanaque Brasileiro

Garnier (1903-1914). Belo Horizonte: Humanitas, 2005.

ENDERS, Armelle. Como se poderia escrever a história do Brasil. Variações acerca do romance nacional do império à república. In: FERREIRA, Marieta de Moraes (Org.). Memória e identidade nacional. Rio de Janeiro: FGV, 2010. p. 59-80.

. "O Plutarco brasileiro": a produção de vultos nacionais no Segundo Reinado. Estudos

Históricos, Rio de Janeiro, v. 14, n. 25, p. 41-62, 2000.

FAGUNDES, Luciana P. Do exílio ao panteão: d. Pedro II e seu reinado sob o(s) olhar(es) republicano(s). Tese (Doutorado em História) — PPHPBC/FGV, Rio de Janeiro, 2012.

FUREIX, Emmanuel. La France des larmes: deuils politiques à l'âge romantique (1814-1840). Seyssel: Champ Vallon, 2009.

GAUCHET, Marcel. Le désenchatement du monde. Paris: Gallimard, 1985.

GIESEY, Ralph E. The royal funeral cerimony in Renaissance France. Genebra: Librarie Droz, 1960. GOMES, Angela de Castro. A república, a história e o IHGB. Belo Horizonte: Argumentum, 2009. . História e historiadores. Rio de Janeiro: FGV, 2013.

. História, historiografia e cultura política no Brasil: algumas reflexões. In: SOIHET,

Rachel; BICALHO, Maria Fernanda B.; GOUVÊA, Maria de Fátima S. Culturas políticas: ensaios de história cultural, história política e ensino de história. Rio de Janeiro: Mauad, 2005. p. 21-44. 
; MOURÃO, Alda (Org.). A experiência da Primeira República no Brasil e em Portugal. Rio de Janeiro: FGV, 2011.

GONÇALVES, João Felipe. Enterrando Rui Barbosa: um estudo de caso da construção fúnebre de heróis nacionais na Primeira República. Estudos Históricos, Rio de Janeiro, v. 14, n. 25, p. 135-161, 2000.

GONTIJO, Rebeca. O velho vaqueano. Capistrano de Abreu (1853-1927): memória, historiografia e escrita de si. Rio de Janeiro: 7Letras, 2013.

GUIMARÃES, Lucia Maria Paschoal. Da Escola Palatina ao Silogeu: Instituto Histórico e Geográfico Brasileiro (1889-1938). Rio de Janeiro: Museu da República, 2006.

. Debaixo da Imediata Proteção de Sua Majestade Imperial: o Instituto Histórico e Geográfico Brasileiro (1838-1889). Rio de Janeiro. RIHGB, Rio de Janeiro, v. 156, n. 388, p. 459613, jul./set. 1995.

. Os funerais de d. Pedro II e o imaginário republicano. In: SOIHET, Rachel; ALMEIDA, Maria R. C. de; AZEVEDO, Cecília; GONTIJO, Rebeca (Org.). Mitos, projetos e práticas políticas: memória e historiografia. Rio de Janeiro: Civilização Brasileira, 2009. p. 69-82.

GUIMARÃES, Manoel Luís Salgado. Historiografia e nação no Brasil (1838-1857). Rio de Janeiro: EdURJ, 2011.

. Nação e civilização nos trópicos: o IHGB e o projeto de uma história nacional. Estudos Históricos, Rio de Janeiro, n. 1, p. 3-27, 1988.

HANSEN, Patrícia Santos. Brasil, um país novo: literatura cívico-pedagógica e a construção de um ideal de infância brasileira na Primeira República. Tese (Doutorado em História), Universidade de São Paulo, São Paulo, 2007.

HOLANDA, Sérgio Buarque de. Raízes do Brasil. São Paulo: Companhia das Letras, 1995. . Visão do paraíso. São Paulo: Brasiliense, 1998.

HOMEM, Amadeu C.; SILVA, Armando M.; ISAÍA, Artur César (Coord.). Progresso e religião: a república no Brasil e em Portugal. Coimbra: Imprensa da Universidade de Coimbra, 2007.

HRUBY, Hugo. O templo das sagradas escrituras: o Instituto Histórico e Geográfico Brasileiro e a escrita da história do Brasil (1889-1912). História da Historiografia, n. 2, p. 50-66, 2009.

KANTOROWICZ, Ernst H. Os dois corpos do rei. São Paulo: Companhia das Letras, 1998. LEFORT, Claude. A invenção democrática: os limites da dominação totalitária. Belo Horizonte: Autêntica, 2011.

. Pensando o politico: ensaios sobre democracia, revolução e liberdade. Rio de Janeiro: Paz e Terra, 1991.

MAUAD, Ana Maria. Imagem e autoimagem do Segundo Reinado. In: NOVAIS, Fernando. História da vida privada no Brasil. São Paulo: Companhia das Letras, 1997. v. 2.

MARCELINO, Douglas Attila. A narrativa histórica entre a vida e o texto: apontamentos sobre um amplo debate. Topoi: Revista de História, v. 13, p. 130-146, 2012.

. Funerais de presidentes e cultura política republicana. In: DELGADO, Lucilia de Almeida

Neves; FERREIRA, Marieta de Moraes (Org.). História do tempo presente. Rio de Janeiro: FGV, 2014. p. 194-210.

. O corpo da Nova República: funerais presidenciais, representação histórica e imaginário político. Rio de Janeiro: FGV, 2015.

. Os funerais como liturgias cívicas: notas sobre um campo de pesquisas. Revista Brasileira de História, v. 31, p. 125-144, 2011.

MELLO, Maria Tereza Chaves de. A república consentida: cultura democrática e científica no final do império. Rio de Janeiro: FGV/Edur, 2007.

MONOD, Jean-Claude. La querele de la sécularization: de Hegel à Blumenberg. Paris: J. Vrin, 2002. MORAIS, A. P.; PIRES, A. P.; TEIXEIRA, J. A.; PEREIRA, J. E.; ROLLO, M. F.; ALMEIDA, P. T. de; CASTELO-BRANCO, S. (Org.). Pensar a república: 1910-2010. Coimbra: Almedina, 2014.

NAXARA, Márcia Regina C. Cientificismo e sensibilidade romântica: em busca de um sentido explicativo para o Brasil no século XIX. Brasília: UnB, 2004.

NEVES, Lúcia Maria B. P. das; GUIMARÃES, Lúcia Maria P.; GONÇALVES, Márcia de Almeida; GONTIJO, Rebeca (Org.). Estudos de historiografia brasileira. Rio de Janeiro: FGV, 2011.

OLIVEIRA, Eduardo Romero de. O império da lei: ensaio sobre o cerimonial de sagração de d. Pedro I (1822). Tempo: Revista do Departamento de História da UFF, v. 13, p. 133-159, 2009. OLIVEIRA, Lúcia Lippi. As festas que a República manda guardar. Estudos Históricos, Rio de Janeiro, v. 2, n. 4, p. 172-189, 1989. 
OLIVEIRA, Maria da Glória de. Escrever vidas, narrar a história: a biografia como problema historiográfico no Brasil oitocentista. Rio de Janeiro: FGV, 2011.

OLIVEIRA, Ricardo de. Os Sertões e a invenção de um Brasil profundo. Revista Brasileira de História, São Paulo, v. 22, n. 44, p. 511-537, 2002.

OZOUF, Mona. La fête révolutionnaire, 1789-1799. Paris: Gallimard, 1976.

. Le Pantheón, l'École Normale des morts. In: NORA, Pierre (Ed.). Les lieux de memóire: la république. Paris: Gallimard, 1984. p. 139-166.

PINTASSILGO, Joaquim. República e formação de cidadãos: a educação cívica nas escolas primárias da Primeira República portuguesa. Lisboa: Colibri, 1998.

PORTO-ALEGRE, Manuel Araújo de. Iconographia Brazileira. RIHGB, n. 23, p. 351, 1856.

REIS, José Carlos. Capistrano de Abreu [1907]. O surgimento de um povo novo: o povo brasileiro. Revista de História, USP, n. 138, p. 63-82, 1998.

RIBEIRO, Lia. A popularização da cultura republicana. Coimbra: Imprensa da Universidade de Coimbra, 2011.

RIVIÈRE, Claude. Les rites profanes. Paris: PUF, 1995.

ROCHE, Daniel. Le siècle des lumières en province: académies et académiciens provinciaux, 1680-1789. Paris/Haia: Mouton, 1978.

. Les républicains des lettres: gens de culture et Lumières au XVIII ${ }^{\mathrm{e}}$ siècle. Paris: Fayard, 1988. ROMERO, Silvio. A história do Brasil ensinada pela biografia de seus heróis. Rio de Janeiro: Livraria Alves e Cia., 1890.

ROSANVALLON, Pierre. Por uma história do político. São Paulo: Alameda, 2010.

SCHWARCZ, Lilia Moritz. As barbas do imperador: d. Pedro II, um monarca nos trópicos. São Paulo: Companhia das Letras, 1998a.

. O olho do rei. As construções iconográficas e simbólicas em torno de um monarca tro-

pical: o imperador d. Pedro II. In: FELDMAN-BIANCO, Bela; LEITE, Miriam L. Moreira (Org.). Desafios de imagens: fotografias, iconografia e vídeo nas ciências sociais. São Paulo: Papirus, 1998b. SEVCENKO, Nicolau. Literatura como missão: tensões sociais e criação cultural na Primeira República. São Paulo: Companhia das Letras, 2003.

SILVA, Armando M. da Silva; CARNEIRO, Maria Luiza T.; SALMI, Stefano (Coord.). República, republicanismo e republicanos: Brasil, Portugal, Itália. Coimbra: Imprensa da Universidade de Coimbra, 2011.

SIMAS, Luiz Antônio. Floriano Peixoto e o mito de salvador da república brasileira. Dissertação (Mestrado em História Social), Universidade Federal do Rio de Janeiro, Rio de Janeiro, 1994.

SOUSA, Francisco Gouvea de. Entre fronteiras e nações: um estudo sobre as revistas do Instituto Histórico Geográfico e Etnográfico Brasileiro entre os anos de 1870 a 1890. Tese (Doutorado em História), PUC-Rio, Rio de Janeiro, 2008.

SOUZA, Adriana Barreto de. Duque de Caxias: o homem por trás do monumento. Rio de Janeiro: Civilização Brasileira, 2008.

SOUZA, Iara Lis S. C. Entre trajetórias e impérios: apontamentos de cultura política e historiografia. Tempo, v. 14, n. 27, p. 23-35, 2009.

1999.

Pátria coroada: o Brasil como corpo político autônomo (1780/1831). São Paulo: Edunesp,

TORGAL, Luís Reis; MENDES, José M. A; CATROGA, Fernando. História da História em Portugal: séculos XIX-XX. Lisboa: Círculo de Leitores, 1996.

VENÂNCIO, Giselle M. Comemorar Camões e repensar a nação: o discurso de Joaquim Nabuco na festa do tricentenário de morte de Camões no Rio de Janeiro (1880). Revista Brasileira de História, São Paulo, v. 33, n. 65, p. 277-290, 2013.

. Uma festa luso-brasileira? As comemorações do tricentenário da morte de Camões no Rio de Janeiro em 1880. In: SARMENTO, Cristina Montalvão; GUIMARÃES, Lúcia Paschoal. Culturas cruzadas em português: redes de poder e relações culturais (Portugal-Brasil, séculos XIX-XX). Coimbra: Almedina, 2012. p. 27-52.

VENTURA, Roberto. Estilo tropical: história tropical e polêmicas literárias no Brasil, 1870-1914. São Paulo: Companhia das Letras, 1991.

VERISSIMO, José. A educação nacional. Porto Alegre: Mercado Aberto, 1985.

WERNECK, Maria Helena. O homem encadernado: Machado de Assis na escrita das biografias. Rio de Janeiro: Eduerj, 2008. 